\title{
Psychometric Factors in Human Capital Research: Identification and Modeling of Employee Groups
}

\author{
Anna Aletdinova, Maxim Bakaev \\ Automated Control Systems department \\ Novosibirsk State Technical University \\ Novosibirsk, Russian Federation \\ aletdinova@corp.nstu.ru; bakaev@corp.nstu.ru
}

\begin{abstract}
Post-industrial economy is shaped by both digitalization, i.e. network-based co-ordination of relations, advanced development of service industry, increase in the number of open innovations, and by deep changes in the role of human and knowledge. The development of Information society can provide competitive advantages for a country in the world economy, as cyberspace enhances intellectual and emotional human resources, broadens cognitive, creative and communication skills, thus allowing boosting the human capital. Our paper is dedicated to studying the factors of education, work experience and personal features (psychometric factors) with respect to their effect on wages and overall identification of employee groups. In this, we employ labor market statistics (both traditional one and collected from online sources with a dedicated software system) and psychological diagnostics methods, which we modified according to our tasks. In our current work, two groups of employees were identified based on the above factors and enhanced Mincer model's quantitative evaluations: freelancers and full-time employees. We particularly consider the effects of education level and type (including open education), work experience, residence location, and personal features on wages in the Siberian Federal Okrug.
\end{abstract}

Keywords-information society; human capital; freelance; Mincer model; web scraping

\section{INTRODUCTION}

The transition towards innovative economy and the revolution in information-communication technologies (ICT) transform social and labor relations as well. The life of an individual had always depended on his or her physical conditions and in-formation processing capabilities receiving, reacting and using in decision-making. The following major components in intensification of information processes were identified [1, 2, 3]: steady increase in information transition speed; growing volumes of the transmitted information; speed up of information processing;

more complete utilization of feedback; extension of new information extraction and use; visualization of information in management; advances in technical tools to support management.

Within the evolution of social and labor relations in digital economy, the search for sustainable forms of development continues. The increase in the quantity and intensity of information flows, the transition to e-society, and the emergence of remote employment has re-shaped the requirements to staff. The foundations of the social evolution theory were laid by the works of D. Bell [4], who wrote about pre-industrial, industrial and post-industrial society, of $\mathrm{R}$. Inglehart [5], on modernization and post-modernization, of $\mathrm{S}$. Lash and S. Crook [6, 7], who characterized pre-modern, modern and post-modern stages in the social development. A. Toffler identified the three waves of the humanity development: agricultural, industrial and post-industrial [8], while A. Giddens talked about traditional and modern epochs and P. Drucker reasoned about particular features of capitalist and post-capitalist society $[9,10]$. The use of similar but differently named concepts later lead to discussions regarding the feasibility of using the term "information society", which ultimately became the most popular one. Most often, researchers relate culture and technological advances with post-modernism considering ICT as the "quintessence of postmodern structure and way of life" $[11,12,13]$ and focus on technologies as the factor for removing reality in the implosion of different cultural spaces [14]. The social stratification and to some extent the residence location affect the shaping of information society, but these factors are smoothened in the nearest perspective. Again, these substantial changes let to the change in professionals' training paradigm, that is, from qualification-based to competencebased model. Further, in the context of the innovative economy, transition to the sixth techno-economic paradigm, and network interactions, the demand for professionals in certain industries, such as nano-technologies, energy saving, artificial intelligence, etc. has increased dramatically (Table I).

TABLE I. THE MAJOR CHANGE FACTORS IN PROFESSIONALS' TRAINING

\begin{tabular}{|l|l|l|}
\hline \multirow{2}{*}{ Characteristics } & \multicolumn{2}{|c|}{ Period } \\
\cline { 2 - 3 } & \multicolumn{1}{|c|}{ Past } & \multicolumn{1}{c|}{ Present } \\
\hline Economy type & Resource & $\begin{array}{l}\text { Innovative } \\
\text { Transition to energy- } \\
\text { saving technologies, } \\
\text { nano-electronics, } \\
\text { artificial intelligence } \\
\text { systems }\end{array}$ \\
\hline Society type & Industrial (see [4,8]) & $\begin{array}{l}\text { Information (see [15, } \\
16,17] \text { ) }\end{array}$ \\
\hline $\begin{array}{l}\text { Professionals' } \\
\text { training } \\
\text { educational } \\
\text { paradigm }\end{array}$ & $\begin{array}{l}\text { Qualification-based } \\
\text { model }\end{array}$ & $\begin{array}{l}\text { Competence-based } \\
\text { model }\end{array}$ \\
\hline
\end{tabular}

The "Atlas of New Professions" edition lists 10 metaprofessional competences essential in innovative economy 
[18]: systems thinking, inter-industry communication, project management, lean production, programming, robotics, intelligence, customer orientation, multi-language and multiculture, working with people, in uncertainty conditions, and creativity. The emerging new professions indeed require solid skills in software tools use, as the changes in the staff functions and established network interaction has led to extension of employment forms, changes in work schedules, erosion of territorial boundaries, flexibility of labor, and transition of economic and social activities into online environment. To maintain competiveness, companies have to innovate and employees have to adjust their behavior within a certain innovative culture. The key competences of new society will be: capability and willingness towards life-long education, permanent self-development, re-education and selflearning, professional mobility, openness to novelty; critical thinking ability; capability and willingness towards reasonable risk, creativity and entrepreneurship, working independently and in team, as well as in highly competitive environment; extensive capabilities in foreign languages as communication tools for effective participation in globalization processes, including fluent communication in business and casual English. The place and role of human in the modern organization is changing - this is no longer an executor, but an object and subject of management. The new managerial paradigm, based on "Human being management" is arising, and the success of organization will by and large depend of intelligent employees, who make use of ICT and can create innovations - so, battle for the talents has already began [19, $20,21]$. Recent global technological and economic trends contribute to eradication of the traditional employment model (with connection to a stable workplaces), implying a concrete employer, permanent contract, full-time occupation, clear positions and promotion prospects. Gradually, the key workrelated terms of post-industrial society (work history, agreement, workplace, work time) are replaced with new ones: mobile workplace, flexible schedule, fixed term contract. New forms of the subject on the labor market emerged - basically, flexible (unstable) forms of employment. The fickleness of social-labor relations, frequent change of work place, having several employers have become a life norm, as the employment model became diffused, inclusive of flexible and non-standard industrial interaction. Particularly, the development of ICT led to increased popularity of freelance work in Russia, among the advantages of which are: flexible schedule, self-management of work days and days off, including vacations, self-planning of leisure activities. Besides, the work with many customers, network interaction, coverage of several adjoining fields, result in increased development of inter-cultural and network communications, tolerance, and general experience. High competition of labor market, non-trivial and non-standard tasks require not just high professional level, but its constant growth and obtainment of new competences, which in turn result in human capital accumulation. High labor mobility is achieved based on active ICT use and it allows aligning free-lance work with full-time labor contract. The development of new projects also often results in innovations, which can be considered an advantage as well.
On the other hand, disadvantages of freelance work are: potentially unlimited duration of work hours, long time spent on the computer, dependence of days off and vacations ability on the previous work performed, no sick-leave payments or some-times no medical insurance whatsoever. This implies additional physical and psycho-logical loads, higher health risks, lack of work safety and health regulations or compensations in case of disabilities. Also, companies don't invest into freelancers' training: educational, professional, competence increase, mentoring, etc. According to the survey that we undertook earlier, freelancers are mostly males $(78 \%)$ working on temporary contracts, and the most popular offers are in the following fields: web design, IT and programming, marketing and advertisement, graphic design, web development, design and art, translating and text processing, outsourcing and consulting [22]. Finally, high labor mobility leads to high inequalities in work amounts between freelancers and, correspondingly, income inequality. Thus, freelance work is characterized by self-organization, higher health risks, working with many different customers with different needs, high adaptability in ever-changing environment, constant selfeducation and innovations creation.

On overall, the transition to the network economy caused extension in the forms of social and labor relations, as well as accumulation of human capital in new branches of economic activities. In our work, we study the human capital features that act as wage differentiation factors, for employees with standard and non-standard forms of employment, which provide competitive advantage for them in the cyberspace. In Section 2 we outline several different existing approaches in human capital research, while in Section 3 we present concrete results of several studies that we undertook for labor markets of selected regions of the Siberian Federal Okrug.

\section{METHODS IN HUMAN CAPITAL RESEARCH}

\section{A. Related Work}

The concept of the human capital was already introduced by William Petty and Adam Smith: the latter in his book infamous book "An Inquiry into the Nature and Causes of the Wealth of Nations" insisted that wages must compensate or equalize the difference in advantages and disadvantages of various kinds of job [23]. This notion of the differences' equalization, put forward by A. Smith, became the basis of the modern concept of investment in human capital, and several researchers have proven the lead of human capital accumulation compared to material one, having received quantitative values for education's contribution to economic growth.

So, E. Denison based on data of 1929-1982 analyzed economic growth and proven that it's mostly determined by the quality of work force, rather than the quantity of production factors engaged. For the production output increase per capita, education was the major factor [24]. G. Becker evaluated the particular normative returns for college graduates, based on data from censuses in 1940, 1950 and later. His estimations for the returns were $14.5 \%$ in $1939,13 \%$ in $1949,12.4 \%$ in 1956 , and $14.8 \%$ in 1958 ; and for high schools the corresponding values were $16 \%, 20 \%, 25 \%$ and $28 \%$ [25]. Basically, an additional year of an employee's 
education in the USA at that time would increase the wage by the return rate. Research by $\mathrm{A}$. Fuente and A. Ciccone suggested that an additional year of education increased individual wage by $6.5 \%$ in European countries on average, and this effect reaches $9 \%$ for EU member countries with less regulated labor market. Further, an additional year of work experience increased the wage by almost another 5\% [26]. According to these authors, in a "typical" OECD country human capital provided up to $22 \%$ of reported growth in work productivity during 1960-1990 period and was responsible for up to $45 \%$ of differences in average productivity for these countries in the 1990s [26]. As G. Psacharopoulos and H. Patrinos noted, the individual education return rate is usually higher than the corresponding social return rate, if the latter is defined based on evaluations of private interests and common (private and social) costs [27].

Futher, J. Mincer proposed the earnings function that relates logarithm of employee's wage to the years of schooling, work experience, work time, and other factors. He demonstrated that the coefficient for the varying schooling years' factor is equal to the internal return rate, which allowed to greatly simplify the education investment efficiency evaluation [28]. A particularly interesting example of the schooling return rate evaluation in Russia is the research work by a large group of authors who considered the differentiation factors for the wages (monthly salaries and hourly wages) by education level, experience, age and professional status in 2005 [29]. When calculating the standard Mincer's equation, the economic return for higher education turned out to be about $82 \%$ (in comparison to the standard high school education), i.e. about $16 \%$ for every year in higher school [29]. The evaluation of the social return for education performed under the supervision of V. Gimpelson and R. Kapelyushnikov for Russian data including state expenses on education but excluding social benefits from it, resulted in the following values for men and women respectively: $16.4 \%$ and $10.4 \%$ in $1995,6.7 \%$ and $8.8 \%$ in 2005 - so there was the decreasing trend during the 1995-2005 decade [30].

All in all, there were a great number of the respective research efforts, but the resulting estimations differ significantly, as one can see from [22-26]. As macroeconomic evaluations include most of the inducted external benefits, while microeconomic ones include only a part of them, the difference between the evaluations can be interpreted as the measure of externalities, resulting from the human capital.

\section{B. Labor Statistics Supplemented with Online Data}

Collecting data on employees' characteristics is essential, as it allows facilitation of decision-making on labor market. The corresponding statistics can be obtained via the following means: from statistical reports published by governmental statistics offices, which are based on population censuses, statistics forms submitted by companies, and occasional sampling surveys; by collecting available data from online sources affiliated with labor market; from individual studies performed by scientific teams, rating agencies, etc. All of the above means have certain disadvantages, see Table II. Particularly, online data collection from websites, e.g. from employment centers, can allow obtaining timely information, although there may be problems with selecting the data sources and subsequent uniform structuring of the collected data. In turn, individual studies are often chaotic, as they seek to satisfy a particular customer and can employ very diverse and novel methods.

The website of the Russian Federal Statistical Service, as of 1 Apr 2017, contains statistical reports for the topic "Labor market, employment and wages" with aggregated data until 2014.

TABLE II. DISADVANTAGES OF VARIOUS MEANS FOR OBTAINING LABOR MARKED DATA

\begin{tabular}{|c|c|}
\hline Means & Disadvantages \\
\hline $\begin{array}{l}\text { Periodical official } \\
\text { statistical reports }\end{array}$ & $\begin{array}{l}\text { Timing of the reports is not always appropriate } \\
\text { in terms of providing for the needs of potential } \\
\text { users and decision-makers. } \\
\text { The variety of the data is limited; the sets of } \\
\text { reported parameters are conservative. } \\
\text { If methodologies change (the sets are modified), } \\
\text { there are problems with "backwards } \\
\text { compatibility" of the parameters. }\end{array}$ \\
\hline $\begin{array}{l}\text { Online data } \\
\text { collection }\end{array}$ & $\begin{array}{l}\text { Problems with structuring and joining the data } \\
\text { into the general population, since data sources } \\
\text { can be very diverse. } \\
\text { The necessity to maintain and re-configure the } \\
\text { web scraping software, in accordance to changes } \\
\text { in data sources. }\end{array}$ \\
\hline Individual studies & $\begin{array}{l}\text { The studies are oriented towards different goals, } \\
\text { so the data tend to be partial, irregular or semi- } \\
\text { closed. } \\
\text { The applied methods can be unorthodox and } \\
\text { may require corrections prior to the analysis. } \\
\text { Timing is not always appropriate, same as for } \\
\text { the official reports. }\end{array}$ \\
\hline
\end{tabular}

There are also intermediate data (up to March 2017) and the results of the federal statistical monitoring undertaken for wages in certain branches of social sector and science (up to Dec 2016). Even if we exclude from consideration the time lag, the number of the provided parameters is also often insufficient, so the novel methods of online data collection become an appropriate supplement. To facilitate online data collection, we developed software system for labor market monitoring, initially for the City Hall of Novosibirsk, Russia. The architecture of the system embraces three major tiers, divided by functions and launched independently by schedule or by request. First is the data gathering module, responsible for accessing the source websites and scrapping data from web pages. The processing module performs data structuring and information extraction - currently, the one related to vacancies and resumes and their specified properties. This module is also responsible for certain intelligent operations with data, such as auto-classification (the jobs by industries), which is done via natural language processing, and identification of double records that emerge within web source or between several of them.Finally, there's the extendable analysis module, directly responsible for decision-making support and providing capabilities for reports generation, filtering, notifications, etc.

The system was put into operation in 2011 and currently its database contains more than 10 million records on vacancies and resumes for Novosibirsk and certain other 
regions of Siberian Federal Okrug (SFO): Altai krai, Altai Republic, Kemerovo region, Tomsk region, Omsk region, Krasnoyarsk krai. Currently, the main parameters of the labor market monitoring 1) are the number of vacancies and resumes published on the websites; 2) wages proposed (in vacancies) and requested (in resumes).

\section{The Methods Considering Psychological Features}

Another set of human capital research methods are based on modifications proposed by the authors and can be a useful supplement to the methods described above. It's expected that in the future, researchers will have access not just to the official data, but also to data on personal characteristics, psychological features, motivation factors and cognitive skills. So, the research community needs to find new ways to collect these data and make them available for labor market studies [31].

A large body of existing research that we considered ([3134]) lets us presume that the important factors influencing human capital accumulation are entrepreneur capabilities, high success motivation, and achieving the specified goals. For our work we used modifications of the following methods in order to include externalities that emerge due to human capital into the evaluations [28], [35-36]: A. Shubert's risk readiness psychological diagnostics method; T. Elers' psychological diagnostics method for personal success motivation; $Y$. Orlov's method for estimating desire for achievements; J. Mincer's modified model.

Already E. Persinger et al. did specify a new understanding of effects from such factors as risk tolerance, trust and reciprocity, value of autonomy, goal-orientation [37]. A. Shubert's method allows estimation of human behavior reactions in situations associated with uncertainty in life, requiring violation of existing norms and rules. It's recommended for use when assessing candidates for a job involving risk conditions. The test contains 25 questions, each of which allows one of 5 answers corresponding to the scale from -2 to 2: completely agree, rather agree, can't say, rather disagree, completely disagree. Since we are going to use this method together with T. Elers' and Y. Orlov's ones, we must adjust the scale to the values ranging from 0 to 4 . The result of the survey is determined according to the accumulated points (Table III) and allows making the conclusion regarding a person's disposition to risky behavior.

TABLE III. CONCLUSIONS REGARDING A SURVEYED PERSON'S DISPOSITION TO RISKY BEHAVIOR, PER ADJUSTED A. SHUBER'S

\begin{tabular}{|c|l|l|l|}
\hline $\mathbf{N}$ & \multicolumn{1}{|c|}{$\begin{array}{c}\text { A. Shubert's } \\
\text { method points }\end{array}$} & Adjusted points & \multicolumn{1}{c|}{ Conclusions } \\
\hline 1 & Less than -30 & Less than 30 & Too careful \\
\hline 2 & From -10 to +10 & $40-60$ & Intermediate values \\
\hline 3 & More than +20 & More than 70 & Risk-prone \\
\hline
\end{tabular}

The survey can be performed individually or in a group, taking on overall about 7 minutes. The final test evaluation is given for a continuous scale, as variation from the average value - positive replies mean higher risk disposition. The method's author notes than high risk disposition is usually complemented by with low motivation towards failure aversion (in other words, defense). This test provides indecisive results for ranges -30 to -10 and 10 to 20 , which can be considered its disadvantage. However, for our research only high risk disposition is important, which strictly corresponds to the range 20 to 50 or, in adjusted points, from 70 to 100 . So, the interpreted survey results can be presented as shown in Table IV.

The T. Elers' method for assessing personal motivation for success contains 41 test questions.

TABLE IV. Interpretation of A. Shubert's method survey for finding out about risky behavior

\begin{tabular}{|l|l|lr|lc|}
\hline $\mathbf{N}$ & \multicolumn{1}{|c|}{ Points' range } & \multicolumn{2}{|c|}{ Conclusions } & \multicolumn{2}{|c|}{ Interpretation } \\
\hline 1 & {$[0 ; 70)$} & $\begin{array}{l}\text { No high risk } \\
\text { disposition }\end{array}$ & $\begin{array}{l}\text { Not typical for } \\
\text { entrepreneurs }\end{array}$ & for \\
\hline 2 & {$[70 ; 100]$} & $\begin{array}{l}\text { High risk } \\
\text { disposition }\end{array}$ & $\begin{array}{l}\text { Typical } \\
\text { entrepreneurs }\end{array}$ & \multicolumn{2}{|c|}{. } \\
\hline
\end{tabular}

Higher number of total points corresponds to higher motivation, and the possible outcomes of the test are presented in Table V.

TABLE V. CONCLUSIONS REGARDING MOTIVATION FOR SUCCESS PER THE T. ELERS' METHOD

\begin{tabular}{|l|l|l|}
\hline $\mathbf{N}$ & \multicolumn{1}{|c|}{ Number of points } & \multicolumn{1}{c|}{ Conclusions } \\
\hline 1 & $1-10$ & Low motivation to success \\
\hline 2 & $11-16$ & Medium motivation level \\
\hline 3 & $17-20$ & Reasonably high motivation level \\
\hline 4 & More than 20 & Success motivation level is too high \\
\hline
\end{tabular}

In terms of human capital, motivation for success is important, so respondents who get 11 and more points are of interest for our research. The method for assessing the desire for achievement, proposed by Y. Orlov in 1978, is aimed towards studying the respective motivation. The test is recommended for studying the achievement motivation effect on the overall effectiveness of organizations' operation. The survey includes 23 statements, so the assessment scale ranges from 0 to 23 points, and the possible outcomes are given in Table VI.

TABLE VI. THE CONCLUSIONS REGARDING THE RESPONDENTS' DESIRE FOR ACHIEVING THE GOALS, PER THE Y. ORLOV'S METHOD

\begin{tabular}{|l|l|l|l|}
\hline $\mathbf{N}$ & $\begin{array}{c}\text { Number of } \\
\text { points }\end{array}$ & $\begin{array}{c}\text { Motivation } \\
\text { level }\end{array}$ & Conclusions \\
\hline 1 & Up to 9 & 1 \\
\hline 2 & 10 & 2 \\
\hline 3 & 11 & 3 & \\
\hline 4 & 12 & 4 & \\
\hline 5 & 13 & 5 & \\
\hline 6 & 14 & 6 & \\
\hline 7 & 15 & 7 & \multirow{2}{*}{ Hedigh achievement level } \\
\hline 8 & 16 & 8 & \\
\hline 9 & 17 & 9 & \\
\hline 10 & More than 18 & 10 & \\
\hline
\end{tabular}

Similarly to what we stated for the T. Elers' method, for our research respondents with medium or high achievement level are of interest. Let us assume the borderline value of 12 points, corresponding to an employee possessing the motivation for achievement of goals. 
Further, the psychological diagnosis methods can be used in the Mincer's model modification, allowing higher $R^{2}$. The simplified Mincer's equation is:

$$
\ln W_{i}=A+b_{1} h_{i}+g_{1} s_{i}+g_{2} s_{i}^{2}+u_{i}
$$

where $w_{i}-$ is wage in monetary units (rubles); $h_{i}-$ is the $i$ th respondent's education level, in years of schooling; $s_{i}-$ is work experience of the $i$-th respondent.

We believe it is feasible to include additional factors to the model, such as: residence location (allows territorial grading): dummy variable $D_{1}$ equal to 1 for megalopolis and 0 otherwise, dummy variable $D_{2}$ equal to 1 for a regional center and 0 otherwise, dummy variable $D_{3}$ equal to 1 for northern regions and 0 otherwise; risk dispositions (allows reflecting entrepreneur skills): dummy variable $R_{i}$ equal to 1 for high risk disposition and 0 otherwise; motivation for success and achievement (as human capital factors, these two can be considered in composition): dummy variable $H C_{i}$ equal to 1 for high motivations for success and achievement and 0 otherwise.

The extended model then will be:

$$
\begin{aligned}
& \ln W_{i}=A+b_{0} H C_{\mathrm{i}}+b_{1} h_{i}+g_{1} s_{i}+g_{2} s_{i}^{2}+ \\
& +d_{1} D_{1}+d_{2} D_{2}+d_{3} D_{3}+b_{3} R_{i}+u_{i}
\end{aligned}
$$

So, the authors have identified three general approaches for obtaining data on employees' characteristics that could be used for assessing the difference in wages. These are 1) statistical reports composed by respective government offices, 2) data collection from relevant online sources, and 3) individual non-periodical studies performed by scientists, rating agencies, etc. None of these approaches is without disadvantages, so in our research we are combining them to assess externalities emerging due to human capital.

To test the hypothesis of the availability of economic feasibility to open education, the following models were used [38]:

$$
\begin{aligned}
& l n w_{i}=a_{0}+a_{2} h_{i}^{3}+a_{2} s_{i}+a_{3} p_{i}+u_{i} \\
& l n w_{i}=a_{0}+a_{2} h_{i}^{2}+a_{2} s_{i}+a_{3} p_{i}+u_{i}
\end{aligned}
$$

where $\boldsymbol{h}_{i}^{\mathbf{1}}$ - the level of $i$-respondent classical education, $\boldsymbol{h}_{i}^{2}$

years;

- the level of $i$ - respondent classical and open education, years; $p_{i}-$ the gender $i-$ respondent (dummy variable: 2 - male, 1 - female).

\section{THE ANALYSIS RESULTS}

\section{A. Normal Salary Analysis with the Three Approaches}

Using the above three approaches, we got the following results for salaries paid in selected regions of the Siberian Federal Okrug (Fig. 1), all values are given in Russian Rubles (in 2016(II), 1 USD ${ }^{\text {s }} 60$ Rub).

The average values calculated based on online data collected from labor market-related websites are quite close to the ones provided by the official reports of the Federal Statistics Service. The comparative ratio between salaries in vacancies and resumes changes with time, which reflects occasionally emerging demand for high-quality professionals - this was especially notable in such industries as: IT and telecommunication; design and creative jobs; education, science and languages; sales; law; home services; printing, publishing and media; agriculture; insurance; human resources. The last column of the table shows the survey data, and here one can note high difference with the official statistics, which can be explained by relatively small size of the samples (199 participants in 2013, 178 in 2014, 152 in 2015, 181 in 2016).

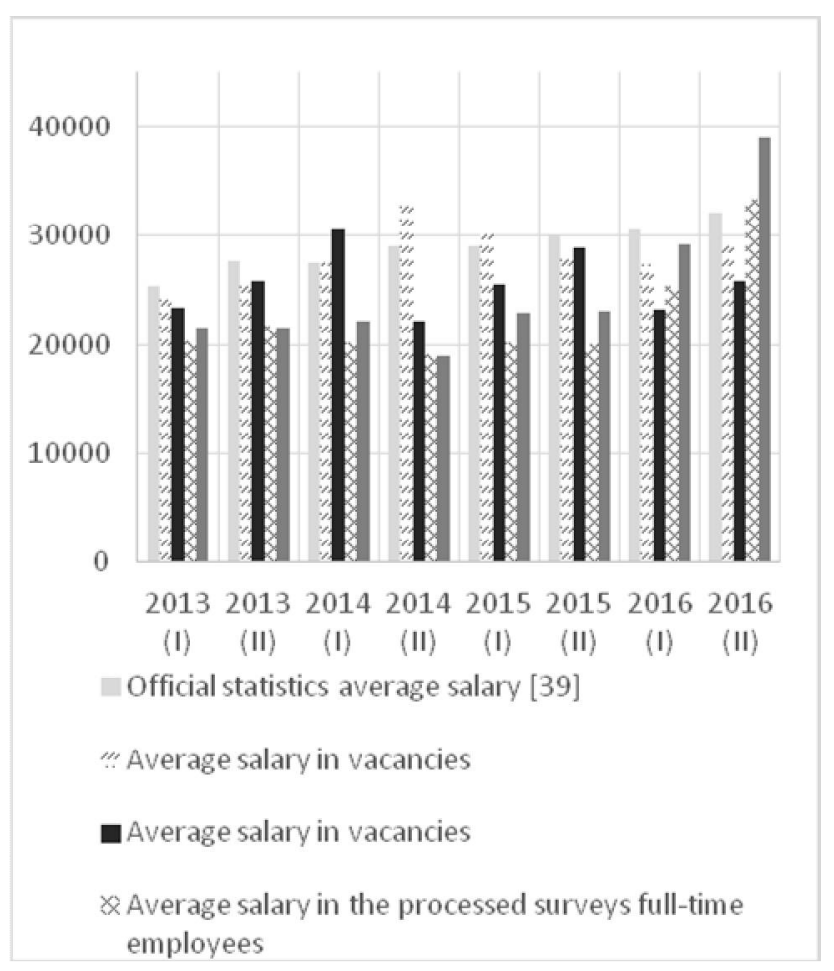

Fig. 1. Changes in average salaries, per time periods (2013-2016)

In 2016, the average wage for freelancers was significantly higher than for full-time employees. From the survey of freelancers in the SFO, their average wages were 28531 rubles in 2015 and already 43288 rubles in 2016. The average work experience for freelancers was 3.4 years, and their average age was 28.1. The number of projects performed simultaneously highly depended of the field and was 1.62 , with the average maximum time without any project reported as 13.5 days. The share of "pure" freelancers (i.e. the ones who didn't have any other job) was $37 \%$, the others being students and graduate students, or employees of some company who consider freelance as extra source of income. The sample sizes were rather small, 325 participants in 2015 and 52 in 2016, but they 
allowed us obtaining curious results regarding psychological characteristics of the workers which we describe below.

\section{B. The Psychological Diagnostics Survey}

The results of the survey based on the psychological diagnostics methods performed by the authors are presented in Table VII.

TABLE VII. THE RESULTS OF PSYCHOLOGICAL DIAGNOSTICS FOR RUSSIAN WORKERS (2014-2016)

\begin{tabular}{|l|l|l|l|l|}
\hline $\begin{array}{c}\text { Type of } \\
\text { workers }\end{array}$ & $\begin{array}{c}\text { Sample } \\
\text { size }\end{array}$ & $\begin{array}{c}\text { Risk } \\
\text { dispo- } \\
\text { sition, } \\
\%\end{array}$ & $\begin{array}{c}\text { Motivation } \\
\text { for success, } \\
\%\end{array}$ & $\begin{array}{c}\text { Motiva- } \\
\text { tion for } \\
\text { goal } \\
\text { achievem } \\
\text { ent, \% }\end{array}$ \\
\hline Freelancers & 376 & 2.93 & 99.2 & 100 \\
\hline $\begin{array}{l}\text { Full-time } \\
\text { (standard } \\
\text { employment) } \\
\text { workers }\end{array}$ & 470 & 15.11 & 36.17 & 34.26 \\
\hline
\end{tabular}

Freelancers had extremely high motivation for success and goal achievement (99.2\% and 100\% respectively) and they are a notable example of human capital. Risk disposition is quite a specific feature, and it was lower than for the standard employment workers. Those individuals, who had high assessments in all the three tests, can be related to the entrepreneurs' category. This was relatively seldom, since most people don't have these features, so the results for the two types of workers considered in our study were quite similar: $2.93 \%$ and $2.77 \%$ respectively. Thus, workers who perform their activities in cyberspace have higher motivation for success and goal-orientation. They are the most competitive ones in the modern environment, and together with high risk disposition they have high potential for promoting innovations in their organization.

\section{The Modified Mincer Model Regression}

We used the modified Mincer model to obtain estimations for the effect of education level, work experience, and several qualitative characteristics of workers on their wage level in Russia in 2014-2016. If a factor wasn't significant, it was removed from the models, which at the end showed high significance:

$$
\begin{aligned}
& \ln W_{i}=0,974+0,421 H C_{\mathrm{i}}+0,047 h_{i}+0,02 s_{i}+ \\
& +0,070 D_{1} h_{i}+0,42 D_{3} h_{i}+u_{i}
\end{aligned}
$$

In (3): $\mathrm{p}<0.001 ; \mathrm{R}^{2}=0.617$; the number of people surveyed 577; coefficients significant at $\alpha=0.01$.

$$
\begin{aligned}
& \ln W_{i}=0,966+0,083 h_{i}+0,005 s_{i}+ \\
& +1,313 D_{1}+1,241 D_{2}+0,790 D_{3}+u_{i}
\end{aligned}
$$

In (4): $p<0.001 ; \mathrm{R}^{2}=0.618$; the number of people surveyed 577; coefficients significant at $\alpha=0.01$.

$$
\begin{aligned}
& \ln W_{i}=0,529+0,0361 H C_{i}+0,062 h_{i}+0,004 s_{i}+ \\
& +1,183 D_{1}+1,041 D_{2}+0,683 D_{3}+0,228 R_{i}+u_{i}
\end{aligned}
$$

In (5): $p<0.001 ; \mathrm{R}^{2}=0.667$; the number of people surveyed
577; coefficients significant at $\alpha=0.05$.

$$
\begin{aligned}
& \ln W_{i}=0,128+0,515 H C_{\mathrm{i}}+0,11 h_{i}-0,0004 s_{i}-0,104 s_{i}^{2}+ \\
& +d_{1} D_{1}+0,022 D_{2}+2,069 D_{3}+0,184 R_{i}+u_{i}
\end{aligned}
$$

In (6): $p<0.001 ; R^{2}=0.540$; the number of people surveyed 577; coefficients significant at $\alpha=0.1$.

So, the self-evaluations of the participants supplement their objective characteristics that were the factors: the worker's education level (schooling years), work experience, residence location, etc. - and all of them were statistically significant in the regression, and are responsible for the wage increase.

The return on education would seem quite low $-4.7 \%$ per schooling year, but it relates to smaller towns. The coefficients for D3hi и D1hi are equal to $4.2 \%$ and $7 \%$ respectively, which means that in larger cities of Siberia the return on education is higher than average and amounts to $8.9 \%$ and even $11.7 \%$ for northern towns. The level of wages, according to our analysis, turned out to be higher in larger cities and northern towns, for any education level and work experience. The introduction of the D1si variable into the model allowed us to find out that for northern regions of Siberia work experience has significant positive effect on wages, more than $+2 \%$ per working year. An additional year in school, unusually, would add only $1 \%$ to the wages - so we can conclude that for resource extraction companies operating in Northern Siberia human capital is of lower importance than practical work experience.

We also performed the analysis for freelancers and standard employment workers, and in 2015 the return on education turned out to be $11.2 \%$ per year. An extra year of work experience increased the wage by $3.6 \%$ for full-time workers and by $7.2 \%$ for freelancers. These values are close to the average ones in Siberia, and the data for 2016 show the beginning of trend towards differentiation of wages, accompanied by their overall growth.

The additional research is based on survey undertaken in 2016 for workers from the Siberian Federal Okrug, with 504 responders, of which 294 did perform self-education through open education. We consider open education as: open online courses provided by dedicated platforms or educational institutions, studying educational literature or multimedia, taking part in professional communities on the Internet or in online conferences. The trend is that the most active in open education are the workers aged 24-43 (Fig. 2). 


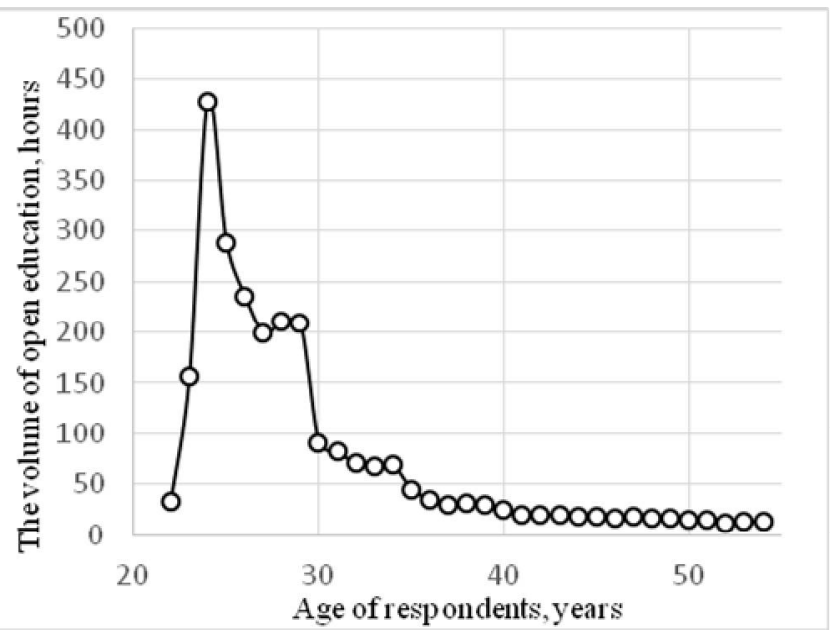

Fig. 2. The dependency between the number of hours in open education and the responders' age

The responders were employees of companies from the Siberian Federal Okrug, who were divided into two groups: those who had only traditional education and those who also obtained open education in any form, including self-education. The reported duration of engagement with open education was quite diverse, ranging from minutes and days to months and years, so the variable was obtained based on expert evaluations of the participants themselves.

The results of the regression analysis for the data of 2016 are presented in Table VIII (all the coefficients are significant). From the model (3), the return on traditional education was $9.4 \%$ for every extra year in education, while an extra year of work experience would increase the wage by $2.9 \%$.

TABLE VIII. THE RESULTS OF REGRESSION ANALYSIS FOR THE MODIFIED MODELS

\begin{tabular}{|l|l|l|}
\hline \multirow{2}{*}{ Item } & \multicolumn{2}{c|}{ Values } \\
\cline { 2 - 3 } & $\begin{array}{c}\text { For the model without } \\
\text { open education (3) }\end{array}$ & $\begin{array}{c}\text { For the model with open } \\
\text { education (4) }\end{array}$ \\
\hline Sample size & 210 & 294 \\
\hline R2 & 0.561 & 0.606 \\
\hline F-criterion & 99.21 & 109.24 \\
\hline $\begin{array}{l}\text { Non-standardized } \\
\text { coefficients }\end{array}$ & & \\
\hline a0 & -0.326 & -0.347 \\
\hline a1 & $0.094^{*}$ & $0.095^{*}$ \\
\hline a2 & $0.029^{*}$ & $0.034^{*}$ \\
\hline a3 & $0.681^{*}$ & $0.698^{*}$ \\
\hline
\end{tabular}

* significant at 0.01

Male workers with traditional education would earn $6.81 \%$ more than female ones, all other factors being equal. From the model (4), the return on traditional education with elements of open education was $9.5 \%$ for every extra year in education, while an extra year of work experience would increase the wage by $3.4 \%$. Male workers with traditional education would earn $6.98 \%$ more than female ones, all other factors being equal. The analysis of the regression models suggests that returns for traditional only and traditional plus open education are nearly the same. This is possibly due to: lack of universal engagement with the open education, the duration of which is often measured merely in minutes and hours; limited sample size; difficulties in expert assessment of the open education duration, leading to potential biases. Still, we would suggest that the difference in the return values will increase in the future, and there's the demand and the need for the open education development in Russia.

\section{CONCLUSIONS}

In post-industrial economy, the roles of information and human capital become particularly important, as employees have to master information-communication technologies, perform life-long self-development and be goal-oriented in their activities. Currently, the Strategy for Information Society Development in Russia in 2017-2030 defines information society development as a new stage in the history of human civilization development. Information and knowledge become the most important production factors and provide countries and companies with decisive competitive advantages, as human capital is capable of creating innovations based on knowledge.

Data for studies related to human capital and labor markets can be obtained from not just traditional sources, such as official statistical reports or individual published studies, but also via collection from online data sources. In our work we analyze particular features of labor market in several Siberian regions and assess externalities that emerge due to human capital. Our research was based on modified methods initially proposed by T. Elers, A. Shubert, and Y. Orlov, as well as on J. Mincer's model. We divided the workers into two groups freelancers and full-time employees - and identified benefits, disadvantages, and prospects of remote work. Using the modified Mincer model, we provided quantitative evaluations for effects of education level, work experience, residence location, and personal character features on wage levels for the two groups. This paper is significantly extended version of our previous publication [40].

\section{ACKNOWLEDGMENT}

The reported study was funded by RHSF/RFBR according to the research project No. 17-32-01087 a2.

\section{REFERENCES}

[1] D. Lyon, "The information society: Issues and illusions," John Wiley \& Sons, 2013.

[2] H. Österle, "Business in the information age: heading for new processes," Springer Science \& Business Media, 2013.

[3] N. Chesley, "Information and communication technology use, work intensification and employee strain and distress," Work, Employment \& Society, T. 28 No. 4, 2014, pp. 589-610.

[4] D. Bell, "Thinking ahead," Harvard Business Review, No. 57(3), 1997, pp. 20-42.

[5] R. Inglehart, "Modernization and postmodernization: Cultural, economic, and political change in 43 societies," Princeton University Press, 1997.

[6] S. Lash, "Critique of Information," Thousand Oaks: Sage Publications, 2002 .

[7] S. Crook, "The end of radical social theory? Radicalism, modernism and postmodernism," In Postmodernism and Society, Macmillan Education UK, 1990, pp. 46-75.

[8] A. Toffler, T. Alvin, "The third wave," New York: Bantam books, 1981, pp. 32-33. 
[9] A. Giddens, "The consequences of modernity," John Wiley \& Sons, 2013.

[10] P. F. Drucker, "Post-capitalist society," Routledge, 1994.

[11] F. Webster, "Theories of the information society," Routledge, 2014.

[12] H. Nowotny, "Time: The modern and postmodern experience," John Wiley \& Sons, 2015.

[13] R. Wilken, "Teletechnologies, place, and community," Routledge, 2014.

[14] D. Ley, "Modernism, postmodernism and the struggleforplace," The Power of Place (RLE Social \& Cultural Geography): Bringing Together Geographical and Sociological Imaginations, 2014.

[15] M. Castells, "End of Millennium: The Information Age: Economy, Society, and Culture," John Wiley \& Sons, Vol. 3, 2010.

[16] A.A. Aletdinova, M.S. Kravchenko, M.A. Bakaev, "Crowdsourcing and the effectiveness of $\mathrm{C} 2 \mathrm{G}$ interaction in Russia," In 3 International conference electronic governance and open society: challenges in Eurasia (EGOSE 2016), New York: ACM PRESS, 2016, pp. 202-211.

[17] V.V. Denisov, G.I. Kurcheeva, V.A. Khvorostov, "Threats to information security in a highly organized system of the "Smart city"," Journal of Physics: Conference Series, vol. 803, 2017, pp. 1-6.

[18] P. Luksha, K. Luksha, D. Varlamova, D. Sudakov, D. Peskov, D. Korichin, "Atlas of new professions," Moscow: Skolkovo, 2014.

[19] E. Michaels, H. Handfield-Jones, B. Axelrod, "The war for talent," Harvard Business Press, 2001.

[20] S. Beechler, I.C. Woodward, "The global "war for talent"," Journal of international management, T. 15, No. 3, 2009, pp. 273-285.

[21] N. Lynton, S. Beechler, "Using Chinese managerial values to win the war for talent," Asia Pacific Business Review, T. 18, No. 4, 2012, pp. 567-585.

[22] A.A. Aletdinova, "Peculiarities of the Russian Freelance Market," Journal of Siberian Federal University. Humanities \& Social Sciences, T. 9, No. 11, 2016, pp. 2734-2741.

[23] A. Smith, "An Inquiry into the Nature and Causes of the Wealth of Nations," Oxford: Oxford Univ. Press, 1976.

[24] E.F. Denison, "Accounting for United States economic growth, 1929$1969, " 1974$.

[25] G. Becker, "Human Capital: a theoretical and empirical analysis, with special reference to education," New York:National Bureau of Economic Research: distributed by Columbia University Press, 1975.

[26] A. de la Fuente, A. Ciccone, "Human capital in a global and knowledgebased economy," In Report for European Comission, 2002, pp.3-4.

[27] G. Psacharopoulos, H.A. Patrinos, "Returns to Investment in Education: A Further Update," The World Bank, Policy Research Working Paper, T. 12, No. 2, 2002, pp. 11-134.

[28] J. Mincer, "Education, Experience, and the Distribution of Earnings and Employment: An Overview. Education, Income, and Human Behavior," New York: NBER, 1975.

[29] V. Gimpelson, A. Lukyanova, "On the poor state worker, say a word ...: intersectoral differences in wages,' Issues of Economics. No. 6, 2006, pp. 81-106.

[30] V.E. Gimpelson, R.I. Kapelyushnikov, T.S. Karabchuk, Z.A. Rizhikova, T.A. Bilyak, "The choice of profession: where did you study and what do you do?" Economic Journal of HSE, No.13(2), 2009.

[31] M.A. Youndt, "Human resource considerations and value creation: the mediating role of intellectual capital," In Paper delivered at National Conference of US Academy of Management, Toronto, 2000.

[32] V. Blazevic, C. Wiertz, J. Cotte, K. de Ruyter, D.I. Keeling, "GOSIP in cyberspace: Conceptualization and scale development for general online social interaction propensity," Journal of Interactive Marketing, No.28(2), 2014, pp. 87-100.

[33] G. Elia, A. Margherita, C. Petti, "Corporate Entrepreneurship: The Antecedents at Individual and Organisational Levels in TechnologyBased Firms," In Creating Technology-Driven Entrepreneurship, Palgrave Macmillan UK, 2016, pp. 49-77.
[34] N. Uysal, "Social collaboration in intranets: The impact of social exchange and group norms on internal communication," International Journal of Business Communication, No.53(2), 2016, pp.181-199.

[35] O.P. Eliseev "Practical work on the psychology of personality," St. Petersburg: Publishing house "Peter", 2003.

[36] J. Mincer, "Schooling, experience and earnings," New York: NBER, 1975.

[37] E.S. Persinger, E. Civi, S.W. Vostina, "The born global entrepreneur in emerging economies," International Business \& Economics Research Journal (IBER), T. 6, №. 3, 2011.

[38] A.A. Aletdinova, M.A. Bakaev, "The Economy of Smart and AI-Based Education," The Social Sciences. Vol. 12, iss. 20, 2016.

[39] GKS. (2017). Retrieved from: http://www.gks.ru/

[40] A. Aletdinova, M. Bakaev, "Human Capital in the Information Society and the Wage Difference Factors," In Proc. of Internet and Modern Society (IMS-2017), Information Technology \& Culture, 2017. (in print) 